\section{Effect of Extended Photoperiod with a Fixed Mixture of Light Wavelengths on Tomato Seedlings}

\author{
Humberto Aguirre-Becerra and Juan Fernando García-Trejo \\ Cuerpo Académico de Bioingeniería, Facultad de Ingeniería, Campus \\ Amazcala. Universidad Autónoma de Querétaro, Chichimequillas-Amazcala \\ Road Km 1 S/N, Amazcala, C.P. 76265, El Marqués, Querétaro, México
}

Cristina Vázquez-Hernández and Aurora Mariana Alvarado

Doctorado en Ingeniería de Biosistemas. Facultad de Ingeniería, Campus Amazcala, Universidad Autónoma de Querétaro, Carr, ChichimequillasAmazcala Road Km 1 S/N, Amazcala, C.P. 76265, El Marqués, Querétaro, México

Ana Angélica Feregrino-Pérez and Luis Miguel Contreras-Medina Cuerpo Académico de Bioingeniería, Facultad de Ingeniería, Campus Amazcala, Universidad Autónoma de Querétaro, Chichimequillas-Amazcala Road Km 1 S/N, Amazcala, C.P. 76265, El Marqués, Querétaro, México

\section{Ramón G. Guevara-Gonzalez \\ Cuerpo Académico de Ingeniería de Biosistemas, Facultad de Ingeniería, Campus Amazcala, Universidad Autónoma de Querétaro, Carr, Chichimequillas-Amazcala Road Km 1 S/N, Amazcala, C.P. 76265, El Marqués, Querétaro, México}

Additional index words. Seedling, light wavelength, extended photoperiod, photomorphogenesis, secondary metabolites

\begin{abstract}
Light is an abiotic factor, and its quality, quantity, and photoperiod can be modulated to work as eustress inductors to regulate plant processes. It is known that red (R), blue (B), farred (FR), and ultraviolet-A wavelengths can promote photomorphogenesis and secondary metabolite production in plants. Several ratios of $R: B$ and the addition of end of-day FR, separately, have beneficial effects on plant development, whereas adding ultraviolet-A enhances the production of secondary metabolites such as phenols. However, the effects of extended photoperiods with a mixture of these four wavelengths and extra end-of-day FR have not been evaluated for plants of commercial interest. The objective of this study was to determine the effects on tomato seedlings ('Saladette', CORDOBA F1) of different overnight photoperiods using a fixed combination of $R(625 \mathrm{~nm}), B(460 \mathrm{~nm})$, FR $(720 \mathrm{~nm})$, and ultraviolet-A $(410 \mathrm{~nm})$. We expected increases in the production of specialized metabolites and the generation of beneficial changes in the seedling biomass and morphology. Four treatments involving overnight artificial light provided by a light-emitting diode (LED) module were established: TC (control), 0 h; T1, 4 hours; T2, 8 hours; and T3, 12 hours. All treatments were subjected to a 12-hour natural photoperiod and 12 hours of overnight artificial light. The experiment lasted 4 weeks, and plants were sampled every week for physical and phytochemical measurements. In general, seedlings subjected to 4-hour and 8-hour treatments presented better results than those subjected to the control and 12-hour overnight photoperiod treatments. Seedlings subjected to treatments with an 8-hour overnight photoperiod presented large accumulation of biomass in the stem rather than in the leaves because they had large stem dry weight, stem weight, and elongation and higher first, second, and third internode lengths; however, they had lower leaf area, leaf dry weight, and health index. Seedlings subjected to treatment with a 4-hour overnight photoperiod were visually bigger, with large leaf expansion, total length, stem weight, total weight, and specific leaf area; however, this treatment had a negative impact on the biomass accumulation, with lower leaf weight, stem dry weight, and health index. The 12-hour treatment had a negative impact on the leaf area, and thus the specific leaf area, of seedlings; however, the biomass accumulation was large, with higher leaf dry weight, total dry matter, and specific leaf area, but no difference in stem dry weight compared with the control. At the end of the experiment, the total phenolic content increased in all treatments compared with the control, but the flavonoid content decreased. Moreover, the antioxidant capacity was higher for T2 during the last 2 weeks of the experiment. Results are discussed according to the possibilities of using this light strategy for seedling production.
\end{abstract}

Light is one of the most important factors for plant growth and development. The light source can be natural, artificial, or a combination of both, and their quantity and quality

lead to different plant development results (Xu, 2019). Positive effects on plant development can be obtained by regulating the dose or exposure time of biotic or abiotic stress factors ("positive stress" or eustress) (Vázquez-Hernández et al., 2019). Light can generate eustress for crop yield improvements or increments in specialized metabolite synthesis (Alvarado et al., 2019). Supplemental lighting promotes the growth of greenhouse-produced vegetable seedlings by increasing the total day light integral (DLI), which can be low because of the combination of short days and cloud cover, thus leading to growth rate reductions (Gómez and Mitchell, 2015). New trends in artificial lighting have shifted toward LED lights because they offer a variety of narrow wavebands to provide specific light spectra to potentially optimize seedlings by stimulating plant photoreceptors that regulate growth and morphology (photomorphogenesis) (Gómez and Mitchell, 2015). The emerging highintensity LED lamps are an alternative for supplemented photoperiods due to their long functional life, low operating temperature, low energy consumption, and selective spectral output (Hernández and Kubota, 2012). Photoperiod extension is a technique that can promote dry matter productivity of greenhouse crops due to an increase in the daily net photosynthetic $\mathrm{CO}_{2}$ assimilation (Matsuda et al., 2016). Tomato is produced widely in the world and is cultivated throughout the year. Due to their importance in crop production, tomato seedlings have been used as a research model in experiments with specific wavelengths and different DLIs. Young tomato plants are mainly produced under controlled conditions on a large scale to meet the increasing production demand, and supplemental lighting is often used to enhance seedling growth and obtain year-round high production and good quality (Fan et al., 2013; Kozai, 2007). During an experiment performed by Fan et al. (2013) involving several light intensities of R/B LEDs and a 12-h photoperiod, tomato cherry seedlings were evaluated and fresh weight, dry weight, and energy efficiency were superior in plants grown under $300 \mu \mathrm{mol} \cdot \mathrm{m}^{-2} \cdot \mathrm{s}^{-1}$ (DLI $=12.96$ $\left.\mathrm{mol} \cdot \mathrm{m}^{-2} \cdot \mathrm{d}^{-1}\right)$; however, plant height and specific leaf area were superior under 50 $\mu \mathrm{mol} \cdot \mathrm{m}^{-2} \cdot \mathrm{s}^{-1}\left(\mathrm{DLI}=2.16 \mathrm{~mol} \cdot \mathrm{m}^{-2} \cdot \mathrm{d}^{-1}\right)$. Similarly, tomato seedlings ('Komeett') were grown with several ratios of $\mathrm{R} / \mathrm{B}$ supplemental lighting under low and high solar DLIs $\left(8.9 \pm 0.9\right.$ and $19.4 \pm 1.9 \mathrm{~mol} \cdot \mathrm{m}^{-2} \cdot \mathrm{d}^{-1}$, respectively), and growth and morphological parameters, including dry shoot mass, leaf count, stem diameter, hypocotyl length, leaf area, and chlorophyll concentration, exhibited the benefits of supplemental light, especially under low DLI; however, there were no significant differences among different $\mathrm{R} / \mathrm{B}$ ratios regardless of the DLI (Hernández and Kubota, 2012).

Plant response to light occurs through small chromophore molecules called photoreceptors that are triggered by specific light wavelengths of the spectral range. Five photosensory systems have been identified: phytochromes that absorb maximally in the $\mathrm{R}$ (600-700 nm) and FR (700-750 nm) ranges; cryptochromes (CRYs 1 and 2) and 
Table 1. Treatments used to evaluate the effects of the extended photoperiod with blue, red, far-red, and ultraviolet-A light on tomato seedlings.

\begin{tabular}{|c|c|c|c|c|c|c|c|}
\hline Treatment & $\begin{array}{l}\text { Photoperiod } \\
\text { regime }(\mathrm{L} / \mathrm{D})\end{array}$ & $\begin{array}{l}\text { Natural light } \\
\text { duration }(\mathrm{h})\end{array}$ & $\begin{array}{l}\text { Artificial light } \\
\text { duration }(\mathrm{h})\end{array}$ & $\begin{array}{l}\text { Activation } \\
\text { hours }\end{array}$ & $\begin{array}{c}\text { Deactivation } \\
\text { hours }\end{array}$ & $\begin{array}{c}\text { Natural } \\
\text { DLI }\left(\mathrm{mol} \cdot \mathrm{m}^{-2} \cdot \mathrm{d}^{-1}\right)\end{array}$ & $\begin{array}{l}\text { Artificial light provided } \\
\text { by lamps }\left(\mathrm{mol} \cdot \mathrm{d}^{-1}\right)\end{array}$ \\
\hline T1 & $16 / 8$ & 12 & 4 & $1900-1930$ & $2300-2330$ & 6.1 & 0.767 \\
\hline $\mathrm{T} 2$ & $20 / 4$ & 12 & 8 & $1900-1930$ & $0300-0330$ & 6.1 & 1.534 \\
\hline T3 & $24 / 0$ & 12 & 12 & $1900-1930$ & $0700-0730$ & 6.1 & 2.302 \\
\hline TC (control) & $12 / 12$ & 12 & 0 & - & - & 6.1 & 0 \\
\hline
\end{tabular}

ultraviolet resistance locus 8 (UVR8) that respond to ultraviolet-A/blue radiation (315$500 \mathrm{~nm})$ and ultraviolet B (ultraviolet-B) wavelengths (280-315 nm); and phototropins and members of the Zeitlupe family that absorb in the blue light (390-500 nm) range (Bantis et al., 2018; Rai et al., 2020). Matsuda et al. (2016) used B, R, and orange light at $150 \mu \mathrm{mol} \cdot \mathrm{m}^{-2} \cdot \mathrm{s}^{-1}$ and white light at 150 and $300 \mu \mathrm{mol} \cdot \mathrm{m}^{-2} \cdot \mathrm{s}^{-1}$ for an overnight extended photoperiod and found that blue light produced leaf damage and stem elongation, whereas R light produced a large leaf weight ratio. Moreover, $\mathrm{B}, \mathrm{R}$, and orange lights resulted in a large leaf area compared with the no-radiation treatment. Several $\mathrm{R} / \mathrm{B}$ ratios have been proposed; in general, these two wavelengths promote stem elongation and production of phytohormones (Matsuo et al., 2019; Nanya et al., 2012; Son et al., 2018). In addition, Xiaoying et al. (2012) reported a higher amount of photosynthetic pigments in leaves of seedlings subjected to blue light treatment.

Ultraviolet-A supplementation has been proven to have beneficial effects on seedlings growth and secondary metabolite production. Mariz-Ponte et al. (2018) found an increase in shoot length, cotyledon area, length/size, and fresh matter in tomato seedlings irradiated with ultraviolet-A, but a reduction in dry matter in some treatments; however, the chlorophyll-a (Chl-a) and chlorophyll-b (Chl-b) contents were unaffected. Kang et al. (2018) showed that ultraviolet-A stimulated plant biomass production in larger leaves and did not induce any stress because the chlorophyll content was unaffected. An experiment involving end-of-day (EOD) FR promoted hypocotyl elongation in 'Aloha' and 'Maxifort' tomato seedlings by increasing the exposition time with lower dose ranges; moreover, none of the EOD FR treatments affected the plant dry weight, stem diameter, or plastochron index (Yang et al., 2012). Similarly, an experiment performed by Eguchi et al. (2016) showed that FR and B

Received for publication 3 Aug. 2020. Accepted for publication 24 Aug. 2020.

Published online 15 October 2020.

We want to thank the members of the Bioengineering Laboratory at Campus Amazcala of Universidad Autonoma de Queretaro. This work was partially financed by CONACYT for awarding the scholarship for Doctorate Degree studies and Articulos $100 \%$ UAQ projects.

J.F.G.-T. is the corresponding author. E-mail: fernando.garcia@uaq.mx.

This is an open access article distributed under the $\mathrm{CC}$ BY-NC-ND license (https://creativecommons.org/ licenses/by-nc-nd/4.0/). synergistically acted to prevent intumescence injury.

The aim of this work was to evaluate the effects of the overnight photoperiod with light comprising a fixed mixture of $\mathrm{R}(625$ $\mathrm{nm})$, B (460 nm), FR (720 nm), and ultraviolet-A $(410 \mathrm{~nm})$ wavelengths on tomato seedlings. Three photoperiods were designed by adjusting the activation/deactivation schedule. All treatments used the same light intensity. Tomato seedlings were selected because this is a crucial crop stage that impacts yield. Additionally, these plants have been used as experimental models when mathematical modeling can be used for further research. The mixture of the four wavelengths, which are considered the dominant wavelengths for plant photoregulation, with extra EOD FR was proposed with the expectation of increasing the specialized metabolite production and generating beneficial changes in seedling morphology. The methodology presents the guidelines for the LED module design, light treatments, and experiment design. Adding overnight light to the natural photoperiod was proposed instead of a complete artificial photoperiod (all day and overnight) for energy-saving because lamps were only activated from 4 to $12 \mathrm{~h}$ per day instead of all day long; this is a commonly used strategy in places where daylight provides an adequate amount of solar radiation. Results have suggested that adding hours of artificial light to the natural photoperiod promotes growth and production of secondary metabolites in tomato seedlings.

\section{Materials and Methods}

Location and plant material. The system was installed at the Universidad Autonoma de Queretaro, Facultad de Ingenieria, Campus Amazcala, which is located in the municipality of El Marques, Queretaro (lat. $20^{\circ} 73^{\prime} \mathrm{N}$, long. $100^{\circ} 26^{\prime} \mathrm{W}, 1920$ m.a.s.l.). Five-hundred twelve seeds of tomato (Solanum lycopersicum L. 'Saladette', CORDOBA F1, Geneva Vegetable Seed, US) were germinated in four 128-cell (3.5- $\times$ $3.5-\mathrm{cm}, 46-\mathrm{mL}$ volume per cell) plug trays with peatmoss and placed in a crystal growth chamber with natural light comprising a photoperiod of $12 \mathrm{~h} / 12 \mathrm{~h}$ light/darkness and DLI of $6.1 \pm 0.5 \mathrm{~mol} \cdot \mathrm{m}^{-2} \cdot \mathrm{d}^{-1}$. The temperature inside the growth chamber was $24.7^{\circ} \mathrm{C} \pm$ $1.3{ }^{\circ} \mathrm{C}$, and the relative humidity was $88.3 \%$ $\pm 5.4 \%$. After the first true leaves emerged (10 d after germination), the trays were placed under light treatments in the same crystal growth chamber. Each treatment contained 110 seedlings (experimental units). Water with a nutrient solution was irrigated directly on the peatmoss every $2 \mathrm{~d}$. The nutrient solution was prepared using highly soluble fertilizer salts to obtain the next ion concentration: $12 \mathrm{meq} \cdot \mathrm{L}^{-1}$ of $\mathrm{NO}_{3}{ }^{-}$; $1 \mathrm{meq} \cdot \mathrm{L}^{-1}$ of $\mathrm{H}_{2} \mathrm{PO}_{4}^{-} ; 7 \mathrm{meq} \cdot \mathrm{L}^{-1}$ of $\mathrm{SO}_{4}{ }^{2-} ; 7$ $\mathrm{meq} \cdot \mathrm{L}^{-1}$ of $\mathrm{K}^{+} ; 9 \mathrm{meq} \cdot \mathrm{L}^{-1}$ of $\mathrm{Ca}^{2+}$; and 4 meq. $\mathrm{L}^{-1}$ of $\mathrm{Mg}^{2+}$. The $\mathrm{pH}$ of the nutrient solution was kept at $6 \pm 0.2$, and the electrical conductivity was kept between 1.6 and $1.8 \mathrm{dS} \cdot \mathrm{mL}^{-1}$.

Experimental setup. Specific lamps were designed for this research. They consisted of a microcontroller that received the signal of a real-time clock (RTC) to activate or deactivate the LED modules at specific schedules. Lamps were programmed to turn on and off progressively during a 30-minute interval simulating sunset and sunrise. The light quantity provided by the LEDs was calculated using Eq. [1] and Eq. [2], where the photon energy $\left(\mathrm{E}_{\text {photon }}\right)$ was calculated according to the light dominant wavelength $(\lambda)$ and considering the light speed (c) and Plank constant (h) (King and Alvarez-Bada, $2020)$; then, the quantity of light $\left(\mu \mathrm{mol} \cdot \mathrm{s}^{-1}\right)$ was calculated using the photon energy calculated using Eq. [1] considering Avogadro's number $\left(\mathrm{N}_{\mathrm{A}}\right)$ and the LED radiant power $\left(R_{p}\right)$, which can be obtained with the lumen value and the relative luminous efficiency function (King and Alvarez-Bada, 2020; Thimijan and Heins, 1983). The LED module consisted of 16 high-intensity R LED lights (ASMT-JR10-AST01， $625 \mathrm{~nm}$; AVAGO Technologies, USA) calculated to provide $24.63 \mu \mathrm{mol} \cdot \mathrm{s}^{-1}, 6$ high-intensity B LED lights (ASMT-JB31-NNP01, 460 nm; AVAGO Technologies, USA) calculated to provide $14.07 \mu \mathrm{mol} \cdot \mathrm{s}^{-1}, 6$ FR LED lights (GF CSHPM1.24-3S4S-1, $721 \mathrm{~nm}$; OSRAM Optosemiconductors, Germany) calculated to provide $8.46 \mu \mathrm{mol} \cdot \mathrm{s}^{-1}$, and 4 ultraviolet-A LED lights (IN-3531SCUV U70, $410 \mathrm{~nm}$; INOLUX, USA) calculated to provide $6.12 \mu \mathrm{mol} \cdot \mathrm{s}^{-1}$. The sum of all wavelengths resulted in $53.28 \mu \mathrm{mol} \cdot \mathrm{s}^{-1}$. The vison angles of the LED lights were a minimum of $125^{\circ}$ and organized homogeneously in an aluminum printed circuit board for correct light distribution.

$$
\begin{gathered}
E_{\text {photon }}=\frac{h c}{\lambda} \\
\mu \mathrm{mol} \cdot \mathrm{s}^{-1}=1 \times 10^{6} \frac{R_{p}}{N_{A} E_{\text {photon }}}
\end{gathered}
$$

The experimental design consisted of a single-factor experiment with three levels and one control (Table 1). Three biological repetitions of seven plants per week were sampled for destructive measurements at the 
beginning of the experiment and during the next 4 weeks. Plug trays were placed randomly in a crystal growth chamber of $42 \mathrm{ft}^{3}$ $(60 \times 130 \times 150 \mathrm{~cm})$ placed in a fully illuminated area for optimal solar radiation; a quantum light sensor was placed inside the chamber for measurement of natural photoperiod and light quantity (Table 1). The growth chamber was divided in sections corresponding to the treatments with solid nontranslucent plastic to avoid artificial light transmission between treatments. The lamp was placed $45 \mathrm{~cm}$ above the plug tray (Fig. 1). Treatment T3 (24 h comprising $12 \mathrm{~h}$ natural light $+12 \mathrm{~h}$ artificial light) was proposed to contrast with treatment $\mathrm{T} 1$ (16 h comprising $12 \mathrm{~h}$ natural light $+4 \mathrm{~h}$ artificial light) and

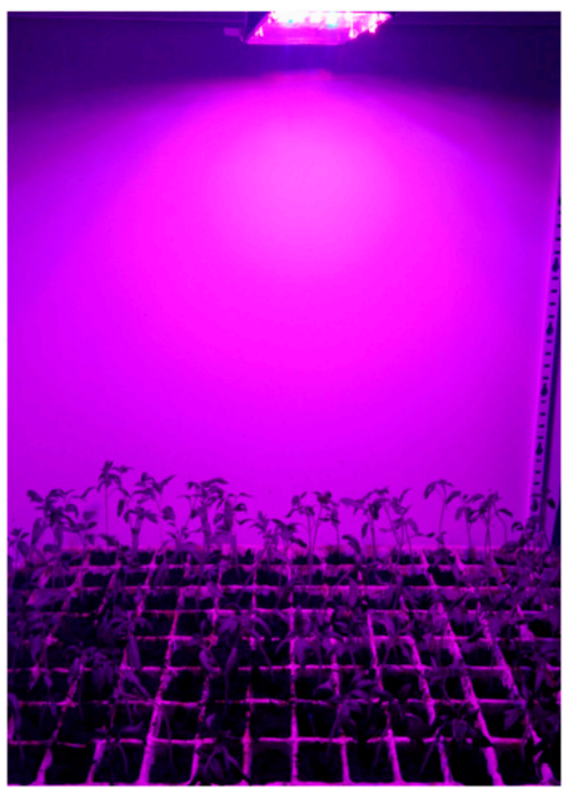

Fig. 1. Lamp disposal $(45 \mathrm{~cm})$ above the plug tray. treatment T2 $(20 \mathrm{~h}$ comprising $12 \mathrm{~h}$ natural light $+8 \mathrm{~h}$ artificial light) because tomato seedlings cannot cope with a 24 -h photoperiod (Velez-Ramirez et al., 2017)

Natural light conditions were measured by sensing solar radiation and photosynthetically active radiation $(P A R)$ light, with the photoperiod lasting from 0730 to $1930 \mathrm{HR}$ and an average DLI of $6.1 \pm 0.5 \mathrm{~mol} \cdot \mathrm{m}^{-2} \cdot \mathrm{d}^{-1}$. The measured artificial light intensity at the foliar level ranged from 15 to $20 \mu \mathrm{mol} \cdot \mathrm{m}^{-2} \cdot \mathrm{s}^{-1}$. Data regarding air temperature, relative humidity, $P A R$ light, and solar radiation were measured every $15 \mathrm{~min}$ with automatic data loggers (Watchdog Model 1000; Spectrum Technologies, Inc., Plainfield, IL), a six-sensor quantum light bar (model 3668I6, LIGHTSCOUT; Spectrum Technologies, Inc.), and a pyranometer (model 3670I, LIGHTSCOUT, Spectrum Technologies, Inc.).

Plant measurements. The total length, stem diameter, and internode length were measured with a Vernier electronic caliper (CD-6-PSX; Vernier, Mitutoyo, Japan; resolution, $0.01 \mathrm{~mm}$; precision, $\pm 0.02 \mathrm{~mm}$ ). The dry weight and ash content were quantified with the method proposed by Olvera-Novoa et al. (1993). The total leaf area was determined in each seedling sample by image processing software in MATLAB. The total length and total weight data were fitted with the least-squares method to a logistic model based on differential Eq. [3] reported by Cavallini (1993), which resulted in Eq. [4], where $f$ is the function of the adjusted variable, $t$ is the time base, $K_{m}$ is the carrying capacity or the maximum population size that a particular environment can support (in this case, corresponds to the maximum predicted length or weigh), $r$ is the maximum growth rate, and $C$ is an arbitrary constant for model correct adjustment depending on the initial conditions. The initial measurements, first week measurements, and second week mea- surements only included the total length, stem diameter, leaf area, leaf weight, stem weight, total dry matter, and total ash content. During the third week of the experiment, the seedlings developed the second internode; therefore, the length of the second internode was included among these data. The information at the end of the experiment included the aforementioned data and leaf fresh weight, leaf dry weight, stem fresh weight, stem dry weight, specific leaf area (SLA), health index, and energy efficiency. The SLA, health index, and the energy efficiency of each seedling was determined using Eq. [5], Eq. [6], and Eq. [7], respectively (Fan et al., 2013).

$$
\begin{gathered}
\frac{d f}{d t}=r f\left(1-\frac{f}{K_{m}}\right) \\
f(t)=\frac{K_{m}}{1+C e^{-r t}} \\
S L A=\frac{\text { Leaf Area }}{\text { Leaf dryweight }}
\end{gathered}
$$

$$
\text { Health index }=\frac{\text { Stem diameter }}{\text { Height }} \times \text { Dryweight }
$$

\section{Energy efficiency}

$$
=\frac{\text { Dryweight }}{\text { Power consumed by LEDs }}
$$

The ash percentage was measured using the Official Methods of Analysis (OMA) of the Association of Official Agricultural Chemists (AOAC). The antioxidant capacity (AOC)

\begin{tabular}{|c|c|c|c|c|c|c|c|c|c|c|}
\hline & $\begin{array}{c}\text { Total } \\
\text { length }(\mathrm{mm})\end{array}$ & $\begin{array}{l}\text { First internode } \\
\text { length }(\mathrm{mm})\end{array}$ & $\begin{array}{l}\text { Second internode } \\
\text { length }(\mathrm{mm})\end{array}$ & $\begin{array}{c}\text { Stem } \\
\operatorname{diam}(\mathrm{mm})\end{array}$ & Stem wt (g) & $\begin{array}{c}\text { Leaf } \\
\text { area }\left(\mathrm{cm}^{2}\right)\end{array}$ & Leaf wt $(\mathrm{g})$ & Total wt $(\mathrm{g})$ & $\begin{array}{c}\text { Total dry } \\
\text { matter (\%) }\end{array}$ & $\begin{array}{c}\text { Total ash } \\
\text { content }(\%)\end{array}$ \\
\hline \multicolumn{11}{|c|}{ Initial measurements } \\
\hline $\mathrm{TC}$ & $77.6 \mathrm{a}$ & - & - & $1.6 \mathrm{a}$ & $0.078 \mathrm{a}$ & $4.5 \mathrm{a}$ & $0.066 \mathrm{a}$ & $0.144 \mathrm{a}$ & $6.7 \mathrm{a}$ & $1.5 \mathrm{ab}$ \\
\hline $\mathrm{T} 1$ & $77.3 \mathrm{a}$ & - & - & $1.6 \mathrm{a}$ & $0.077 \mathrm{a}$ & $4.3 \mathrm{a}$ & $0.063 \mathrm{a}$ & $0.140 \mathrm{a}$ & $6.3 \mathrm{a}$ & $1.3 \mathrm{a}$ \\
\hline $\mathrm{T} 2$ & $75.4 \mathrm{a}$ & - & - & $1.6 \mathrm{a}$ & $0.074 \mathrm{a}$ & $4.4 \mathrm{a}$ & $0.065 \mathrm{a}$ & $0.139 \mathrm{a}$ & $5.8 \mathrm{a}$ & $2.0 \mathrm{~b}$ \\
\hline T3 & $73.1 \mathrm{a}$ & - & - & $1.6 \mathrm{a}$ & $0.072 \mathrm{a}$ & $4.5 \mathrm{a}$ & $0.065 \mathrm{a}$ & $0.138 \mathrm{a}$ & $6.3 \mathrm{a}$ & $2.0 \mathrm{~b}$ \\
\hline \multicolumn{11}{|c|}{ Experiment week 1} \\
\hline $\mathrm{TC}$ & $100.9 \mathrm{~b}$ & - & - & $1.7 \mathrm{a}$ & $0.151 \mathrm{~b}$ & $8.7 \mathrm{a}$ & $0.149 \mathrm{a}$ & $0.301 \mathrm{~b}$ & $12.5 \mathrm{ab}$ & $3.3 \mathrm{a}$ \\
\hline $\mathrm{T} 1$ & $110.1 \mathrm{c}$ & - & - & $1.7 \mathrm{a}$ & $0.175 \mathrm{c}$ & $8.1 \mathrm{a}$ & $0.142 \mathrm{a}$ & $0.317 \mathrm{~b}$ & $11.1 \mathrm{a}$ & $3.3 \mathrm{a}$ \\
\hline $\mathrm{T} 2$ & $94.9 \mathrm{~b}$ & - & - & $1.7 \mathrm{a}$ & $0.145 \mathrm{~b}$ & $8.9 \mathrm{a}$ & $0.151 \mathrm{a}$ & $0.296 \mathrm{ab}$ & $11.8 \mathrm{ab}$ & $3.2 \mathrm{a}$ \\
\hline T3 & $82.2 \mathrm{a}$ & - & - & $1.7 \mathrm{a}$ & $0.121 \mathrm{a}$ & $8.8 \mathrm{a}$ & $0.144 \mathrm{a}$ & $0.264 \mathrm{a}$ & $15.3 \mathrm{~b}$ & $4.0 \mathrm{a}$ \\
\hline \multicolumn{11}{|c|}{ Experiment week 2} \\
\hline $\mathrm{TC}$ & $120.0 \mathrm{a}$ & - & - & $2.0 \mathrm{a}$ & $0.217 \mathrm{a}$ & $17.8 \mathrm{a}$ & $0.316 \mathrm{a}$ & $0.533 \mathrm{ab}$ & $7.0 \mathrm{a}$ & $2.5 \mathrm{a}$ \\
\hline $\mathrm{T} 1$ & $133.9 \mathrm{~b}$ & - & - & $1.9 \mathrm{a}$ & $0.263 \mathrm{~b}$ & $16.6 \mathrm{a}$ & $0.311 \mathrm{a}$ & $0.563 \mathrm{~b}$ & $6.7 \mathrm{a}$ & $2.3 \mathrm{a}$ \\
\hline $\mathrm{T} 2$ & $122.8 \mathrm{ab}$ & - & - & $1.9 \mathrm{a}$ & $0.226 \mathrm{ab}$ & $17.2 \mathrm{a}$ & $0.314 \mathrm{a}$ & $0.540 \mathrm{ab}$ & $7.8 \mathrm{a}$ & $2.3 \mathrm{a}$ \\
\hline T3 & $112.8 \mathrm{a}$ & - & - & $1.9 \mathrm{a}$ & $0.193 \mathrm{a}$ & $17.2 \mathrm{a}$ & $0.307 \mathrm{a}$ & $0.501 \mathrm{a}$ & $7.5 \mathrm{a}$ & $2.2 \mathrm{a}$ \\
\hline \multicolumn{11}{|c|}{ Experiment week 3} \\
\hline $\mathrm{TC}$ & $158.7 \mathrm{a}$ & $27.0 \mathrm{a}$ & $21.5 \mathrm{a}$ & $2.7 \mathrm{a}$ & $0.344 \mathrm{a}$ & $37.8 \mathrm{a}$ & $0.700 \mathrm{a}$ & $1.043 \mathrm{a}$ & $5.7 \mathrm{a}$ & $1.7 \mathrm{a}$ \\
\hline $\mathrm{T} 1$ & $185.2 \mathrm{~b}$ & $33.7 \mathrm{ab}$ & $23.6 \mathrm{a}$ & $2.8 \mathrm{a}$ & $0.431 \mathrm{~b}$ & $36.0 \mathrm{a}$ & $0.691 \mathrm{a}$ & $1.121 \mathrm{~b}$ & $6.2 \mathrm{ab}$ & $1.7 \mathrm{a}$ \\
\hline $\mathrm{T} 2$ & $180.2 \mathrm{~b}$ & $34.1 \mathrm{~b}$ & $37.1 \mathrm{~b}$ & $2.8 \mathrm{a}$ & $0.421 \mathrm{~b}$ & $36.4 \mathrm{a}$ & $0.685 \mathrm{a}$ & $1.107 \mathrm{~b}$ & $6.9 \mathrm{~b}$ & $1.8 \mathrm{a}$ \\
\hline $\mathrm{T} 3$ & $165.4 \mathrm{a}$ & $33.0 \mathrm{ab}$ & $34.3 \mathrm{~b}$ & $2.8 \mathrm{a}$ & $0.366 \mathrm{a}$ & $37.6 \mathrm{a}$ & $0.686 \mathrm{a}$ & $1.052 \mathrm{a}$ & $7.1 \mathrm{~b}$ & $1.8 \mathrm{a}$ \\
\hline
\end{tabular}
of the extracts was evaluated using the free radical test [2,2'-diphenyl-1-picrylhydrazyl

Table 2. Measurements of the total length, first and second internode lengths, stem diameter, stem weight, leaf area, leaf weight, total weight, total dry matter percentage, and total ash content percentage of tomato seedlings at the beginning, first week, second week, and third week of the experiment.

$\mathrm{a}, \mathrm{b}, \mathrm{c}$ in the same column per measurement establish statistical differences per measurement $(P<0.05) . \mathrm{n}=7$ and three biological repetitions per measurement and per treatment.

$\mathrm{T} 1=$ treatment $1 ; \mathrm{T} 2=$ treatment $2 ; \mathrm{T} 3=$ treatment $3 ; \mathrm{TC}=$ control treatment. 


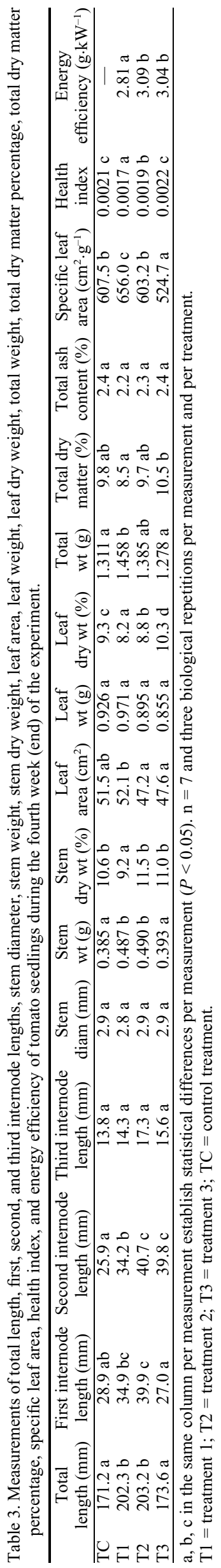

(DPPH)] and ferric ion reduction capacity (FRAP) according to the method described by Corral-Aguayo et al. (2008). Results were expressed as milligrams of Trolox equivalent per gram of dry weight ( $\mathrm{mg} \mathrm{TE} /$ g DW). Chl-a and Chl-b were quantified according to the method described by Strickland and Parsons (1972) with a DR6000 spectrophotometer (HACH Company, Loveland, CO). The content of the total phenolic compounds was determined by the Folin-Ciocalteu method described by Singleton and Rossi (1965) and expressed as milligrams of equivalent gallic acid per gram of dry weight (mg GAE/g DW), and the total flavonoid content was determined by the assay reported by Zhishen et al. (1999) and expressed as milligrams of equivalent of catechin per gram of dry weight (mg CE/g DW).

Statistical analysis. Data were analyzed using a one-way analysis of variance to determine significant differences. When differences were found, Tukey's honestly significant difference test was performed. All statistical analyses were performed with reliability of $95 \%$ using JMP 9.0.1. software (SAS Institute, Cary, NC).

\section{Results}

Physical measurements. Table 2 shows the weekly physiological measurements at the beginning of the experiment and during the next 3 weeks of the experiment. From the second week, the overnight photoperiod stimulated seedling elongation. T1 and T2 presented the highest total lengths; these lengths were $11.57 \%$ and $2.28 \%$ higher than that of the control during the second week and $16.7 \%$ and $13.6 \%$ during the third week, respectively. During the third week, all treatments presented a large internode length. T2 included the highest values of this variable; these values were $26.3 \%$ and $72.6 \%$ higher than that of the control for the first internode and second internode, respectively. The stem diameter remained constant, with no statistical difference between treatments. Seedlings from T1 had superior stem weight values from the first week to the third week $(15.9 \%$, $21.2 \%$, and $25.3 \%$ higher than that of the control, respectively). In contrast, T3 presented the lowest stem weight values of all treatments during the first week $(19.9 \%$ lower than that of the control); however, during the next weeks, it presented considerable recovery but with no statistical difference $(6.4 \%$ higher than that of the control during the third week). The leaf area and leaf weight remained constant, with no statistical difference during the first 3 weeks of the experiment. During the second week, TI and T2 resulted in slightly large total weights, which were noticeable during the third week $(7.5 \%$ and $6.1 \%$ higher values than that of the control, respectively). In contrast, T3 presented the lowest total weight value of all treatments during the first week $(12.3 \%$ lower than that of the control). During the next weeks, considerable recovery occurred; however, that recovery was without statistical difference during the third week. Weight gain of the stem of seedlings subjected to T3 treatment allowed for total weight recovery, but it was not statistically different compared with that of the control. On the contrary, T3 resulted in superior total dry matter, followed by $\mathrm{T} 2$ and $\mathrm{T} 1$, with $23.8 \%, 20.1 \%$, and $7.9 \%$ higher values compared with that of the control during the third week, respectively. The ash percentage remained constant, with no statistical differences among weeks and treatments.

Table 3 shows the measurements at the end of the experiment that indicate the last physiological changes. T1 and T2 continued to result in superior total length $(18.2 \%$ and $18.7 \%$ higher than that of the control, respectively). T2 had large first and second internode lengths $(38.1 \%$ and $57.1 \%$ higher than that of the control, respectively). The stem diameter remained constant, with no statistical difference between treatments. However, seedlings subjected to $\mathrm{T} 1$ and $\mathrm{T} 2$ had the highest stem weights $(26.5 \%$ and $27.3 \%$ higher than that of the control, respectively). In contrast, $\mathrm{T} 1$ resulted in the lowest stem dry weight (13.9\% lower than that of the control). This suggests that seedlings subjected to T2 elongated and also had biomass accumulation in the stem in contrast with those subjected to $\mathrm{T} 1$, which elongated but did not accumulate biomass; those subjected to T3 had higher biomass accumulation but lower height. Moreover, T1 resulted in a large leaf area compared with $\mathrm{T} 2$ and $\mathrm{T} 3$. In contrast, T3 had the highest leaf dry matter value ( $10.561 \%$ higher than that of the control), and $\mathrm{T} 1$ and $\mathrm{T} 2$ had the lowest leaf dry matter values $(11.6 \%$ and $5.5 \%$ lower than that of the control, respectively). This suggest that leaves subjected to $\mathrm{T} 3$ did not have greater expansion but accumulated a large quantity of biomass; T1 had the opposite behavior, with greater expansion but lower biomass accumulation, and $\mathrm{T} 2$ resulted in values between those resulting from T1 and T3. Similarly, T3 resulted in the highest percentage of total dry weight and $\mathrm{T} 1$ resulted in the lowest, but the values were not statistically different than that of the control. However, T1 resulted in the highest value of total fresh weight $(11.2 \%$ higher than that of the control).

The SLA is an important variable in crop growth models because it relates to dry matter production and leaf area expansion, and consequently to light interception and photosynthesis (Gary et al., 1991). A given amount of biomass can be spread over a small or large area. Therefore, T1 resulted in a higher SLA $(8 \%)$, whereas T3 resulted in a lower value $(13.6 \%)$ compared with that of the control. Plants grown under high quantities of light generally have thick leaves and a low SLA, partly due to the extra layers of palisade cells or longer palisade cells that increase the number of chloroplasts and the quantity of 


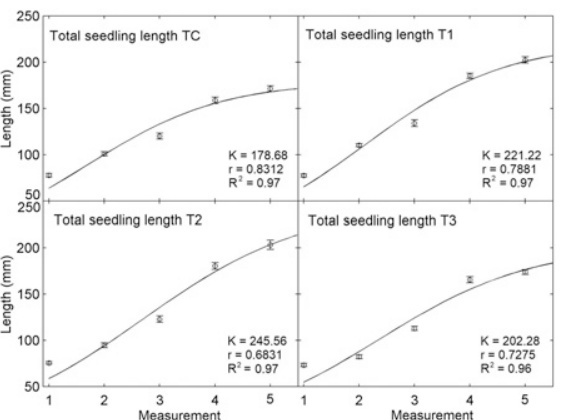

Fig. 2. Total length measurements and data fitted according to the logistic model. $K$ represents the total length predicted by the model, $r$ represents the growth rate, and $R^{2}$ is the correlation coefficient.

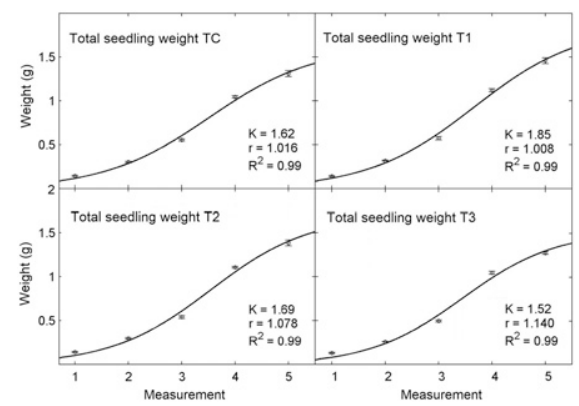

Fig. 3. Total length measurements and data fitted according to the logistic model. $K$ represents the total length predicted by the model, $r$ represents the growth rate, and $R^{2}$ is the correlation coefficient. photosynthetic enzymes. However, with more biomass in a given area, the increase in photosynthetic capacity of the leaves subjected to high quantities of light comes at the cost of having less light capture per unit of biomass at lower irradiances (Björkman, 1981; Evans and Poorter, 2001; Hanson, 1917). The seedling health index is a tool for assessing parameters that directly affect the survival and growth of plants after transplanting, and it can be used to predict crop yields and quality (Korkmaz and Dufault, 2004; Liu et al., 2015). The health index values of T1 and T2 were lower than that of the control because the result of multiplying the stem diameter and dry weight, which did not have significant variation among treatments, was divided by the plant height, the variable of was significantly higher with $\mathrm{T} 1$ and T2. However, the energy efficiency was higher with T2 and T3, thus indicating large biomass production per unit of electric energy consumption.

The logistic model was first used to describe the growth of microorganisms, and it has been widely applied to many ecological problems (Yu et al., 2002). The logistic differential equation is a classic but useful model for describing the dynamics of a onespecies population in an environment with limited resources (Cavallini, 1993). Figure 2 shows the total length measurements and data fitted to a logistic model. $K$ values predicted by the model are consistent with the experimental values because $\mathrm{T} 1$ and $\mathrm{T} 2$ resulted in the highest values and TC and T4 resulted in the lowest. TC had the highest $r$ value because it showed slightly faster growth than all other treatments during the first weeks; however, during the last week, its growth rate significantly decreased. All models of total length had a correlation coefficient greater than 0.96 , thus indicating adequate adaptation to experimental data. Figure 3 shows the total weight measurements and data fitted to the same logistic model. $K$ values predicted by the model were consistent with the experimental values because $\mathrm{T} 1$ resulted in the highest values and TC resulted in the lowest. All models of total weight had a correlation coefficient greater than 0.96 , thus indicating adequate adaptation to experimental data.

Phytochemical measurements. Table 4 shows the weekly phytochemical measurements during the 4 weeks of the experiment. During the initial week of the experiment, the phenolic content did not have significant variation; however, during the last 2 weeks of the experiment, $\mathrm{T} 2$ and $\mathrm{T} 3$ resulted in the highest values for this variable compared with that of the control $(8.3 \%$ and $7.1 \%$ during the third week and $40.3 \%$ and $35.7 \%$ during the fourth week, respectively). Conversely, the flavonoid content was large during the first two measurements, but it considerably decreased during the last three measurements. During the first week, the supplemental light caused this variable to increase with all treatments: $22.1 \%$ with $\mathrm{T} 1$, $40.3 \%$ with T2, and $22.5 \%$ with T3 compared with that of the control. During the last week of the experiment, T1 resulted in the highest value of this variable $(14.8 \%$ higher than that of the control). In general, the AOC (FRAP method) tended to increase with all treatments during the experiment, with the highest

Table 4. Weekly measurements of phenolic and flavonoid content, antioxidant capacity, and chlorophyll (a and b) in tomato seedlings at the beginning and during the 4 weeks of the experiment.

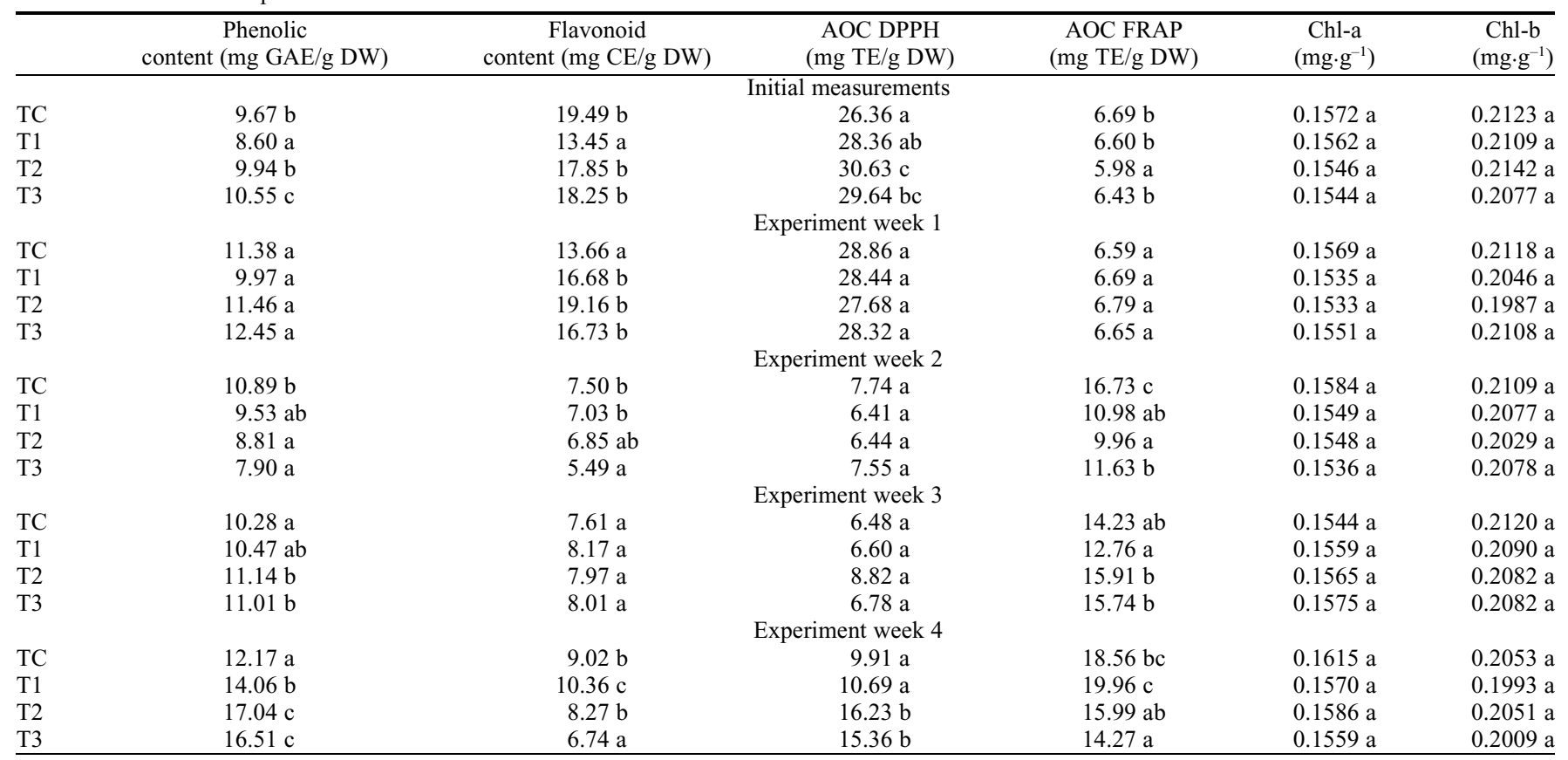

$\mathrm{a}, \mathrm{b}, \mathrm{c}$ in the same column per measurement establish statistical differences per measurement $(P<0.05) . \mathrm{n}=7$ and three biological repetitions per measurement and per treatment.

$\mathrm{AOC}=$ antioxidant capacity $; \mathrm{CE}=$ catechin equivalent $\mathrm{DPPH}=1,1$-diphenyl-2-pycrylhydrazyl; $\mathrm{FRAP}=$ ferric ion reducing antioxidant power; $\mathrm{GAE}=$ gallic acid equivalent; $\mathrm{T} 1=$ treatment $1 ; \mathrm{T} 2=$ treatment $2 ; \mathrm{T} 3=$ treatment $3 ; \mathrm{TC}=$ control treatment; $\mathrm{TE}=$ Trolox equivalent. 
values for $\mathrm{TC}$ and $\mathrm{T} 1$ at the end of the experiment and the lowest values for $\mathrm{T} 2$ and $\mathrm{T} 3$, which were $13.8 \%$ and $23.1 \%$ lower than that of the control, respectively. However, the AOC (DPPH method) decreased considerably after the first week of light exposure and presented a slight increase during the last 3 weeks; T2 and T3 had the largest values, which were $63.8 \%$ and $55 \%$ higher than that of the control, respectively. Measurements of the two types of chlorophyll remained constant, with no significant difference during the entire the experiment.

\section{Discussion}

Some characteristics of properly grown tomato seedlings include short internodes, firm stems, and large and intensive green leaves (Brazaityte et al., 2010; Glowacka, 2002). During this research, $\mathrm{T} 1$ and $\mathrm{T} 2$ resulted in large total lengths and $\mathrm{T} 1$ resulted in a slightly larger leaf area. This was expected because TC and T3 included extreme photoperiodic conditions of the experiment such as no artificial light and $24 \mathrm{~h}$ of light (12 $\mathrm{h}$ of natural light and $12 \mathrm{~h}$ of artificial light). Moreover, this result is consistent with that of Haque et al. (2015), who evaluated the growth of wild and cultivated tomato species under continuous light and no temperature variations; they found that the rate of photosynthesis and the maximum photochemical efficiency of photosystem II declined with the development of leaf chlorosis. The percentages of dry matter during the last week were consistent with that of Brazaityte et al. (2010), with $9.20 \%, 9.60 \%$, and $10.88 \%$ (calculated values) found during measurements 1,2, and 3 of tomato hybrid 'Raissa F1' plants subjected to treatments using $R$, FR, B, and ultraviolet light. During their experiment, this treatment also resulted in the best total length, leaf area, and fresh weight. At the end of the experiment and according to most measurements, $\mathrm{T} 3$ resulted in large dry matter percentages, consistent with the results of Haque et al. (2015), who showed that species of tomato cultivated under continuous light had higher dry matter production due to the continuous photosynthesis and subsequent increase in carbon gain. In the present study, T1 and T2 presented the best results, indicating that in addition to light quality, the photoperiod is an important variable for plant growth. In accordance with the results of Kang et al. (2018) and Mariz-Ponte et al. (2018), the chlorophyll values did not vary significantly between treatments. Furthermore, the stem diameters and chlorophyll quantities did not display statistical differences, consistent with the experiment results reported by Hernández and Kubota (2012), who evaluated ratios of $\mathrm{R} / \mathrm{B}$ with different DLI values for 'Komeett' tomato seedlings. During the same experiment, after $18 \mathrm{~d}$ of treatment with two true leaves, the leaf area did not present a statistical difference, which was consistent with our experiment results, indicating that the leaf area started presenting a statistical dif- ference during the second measurement ( $14 \mathrm{~d}$ of treatment plus $7 \mathrm{~d}$ from germination to the first true leaf). Along with the increase in light intensity, the SLA gradually decreased, and that decrease in the SLA may have reduced the light energy absorption (Fan et al., 2013). The specific leaf area behavior among treatments is consistent because the larger the amount of supplemental light received, the lower the SLA value. Moreover, the SLA values were consistent with those reported by Gary et al. (1991), who obtained values from 450 to $750 \mathrm{~cm}^{2} \cdot \mathrm{g}^{-1}$ during their experiment modeling the daily changes of SLA in tomato TOMGRO.

Antioxidant levels in seedlings could be a standard for field adaptation when environmental changes occur at transplantation (Kim et al., 2014). Plants possess a defense mechanism that uses antioxidant substrates or enzymes to reduce the negative effects of reactive oxygen species (ROS) produced by stressful conditions (Mittler, 2002). Phenolic compounds with antioxidant properties induce better growth and adaptation under stressful conditions (Rivero et al., 2003) and have redox properties that allow them to act as antioxidants and could be used as a basis for rapid screening of antioxidant activity (Baba and Malik, 2015; Soobrattee et al., 2005). Several techniques have been described to evaluate the antioxidant capacity of food and plants; two of these techniques that are widely applied are DPPH and FRAP (Halvorsen and Blomhoff, 2011; Ozgen et al., 2006; Villano et al., 2007). During the experiment performed by Kim et al. (2014), it was found that adding $B$ light increased the phenolic concentration, total flavonoid concentration, and antioxidant capacity compared with other wavelengths. Similarly, the addition of FR to supplemental light considerably increased the production of the total phenolic contents and antioxidant capacities in lettuce (Lee et al., 2016). At the end of our experiment, the quantity of phenolic compounds was higher with all treatments compared with $\mathrm{TC}$, which received no artificial light because $B$ and ultraviolet-A light trigger the biosynthesis of phenolic compounds with antioxidant properties (Bantis et al., 2018). However, the concentration of flavonoids decreased with treatments with the highest amount of artificial light. At the end of the experiment, the quantity of total phenolics increased and the quantity of flavonoids decreased. This indicated that the phenolic compounds, but not the flavonoids, were produced because of the plant response to stress. The increments in the total phenolics contents with treatments $\mathrm{T} 2$ and $\mathrm{T} 3$ at the end of the experiment were consistent with those of the DPPH assay, which is often applied to classify the scavenging activity of phenolic compounds (Nenadis and Tsimidou, 2002). However, with the FRAP assay, the AOC tended to increase with all treatments during the entire experiment and TC and T1 resulted in the highest values at the end of the experiment, contrary to results for DPPH. This is because the FRAP assay has little selectivity, measures almost all reductants (including antioxidants), with a reduction potential less than $0.7 \mathrm{~V}$, does not detect glutathione (GSH) or protein thiols, and is unable to detect other low-molecular-weight thiols and sulfurcontaining molecules that may have a role in the antioxidant defense of plants (Halvorsen and Blomhoff, 2011). Light quality affects endogenous hormones by influencing secondary metabolism. R light may promote stem growth by regulating the biosynthesis of GAs, and B light may promote flavonoid, lignin, phenylpropanoid, and some hormones (OuYang et al., 2015). Extended photoperiods with R, B, FR, and ultravioletA light can regulate elongation and leaf expansion in tomato seedlings. Moreover, adequate antioxidant levels in seedlings can be achieved because this variable is important for adaptation when environmental changes occur at transplantation.

\section{Conclusion}

This investigation revealed that the growth of tomato seedlings 'Cordoba F1' was enhanced under photoperiodic conditions including $12 \mathrm{~h}$ of natural light with 4 and $8 \mathrm{~h}$ of artificial light composed of R, FR, $\mathrm{B}$, and ultraviolet-A wavelengths. Moreover, $24 \mathrm{~h}$ of light did not significantly increase growth or plant total phenolics and flavonoids contents. This study provided basic information about the effects of increasing the DLI trough overnight photoperiod with a combination of four important wavelengths at a morphological level and the production of phytochemicals of interest. This work also provided basic information about the design of a LED module by considering the amount of light that each LED corresponding to a dominant wavelength can proportionate. This information can be considered for further designs of LED-based artificial lighting systems for closed-type plant factories, especially nursery plants, by taking into consideration the amount of natural light hours and extending the photoperiod schedules with artificial light.

\section{Literature Cited}

Alvarado, A.M., H. Aguirre-Becerra, M.C Vázquez-Hernández, E. Magaña-Lopez, I. Parola-Contreras, L.H. Caicedo-Lopez, L.M. Contreras-Medina, J.F. Garcia-Trejo, R.G. Guevara-Gonzalez, and A.A. Feregrino-Perez. 2019. Influence of elicitors and eustressors on the production of plant secondary metabolites, p. 333-388. In: M. Akhtar, M. Swamy, and U. Sinniah (eds.). Natural bio-active compounds. Springer, Singapore. https://doi.org/10.1007/ 978-981-13-7154-7 11.

Baba, S.A. and S.A. Malik. 2015. Determination of total phenolic and flavonoid content, antimicrobial and antioxidant activity of a root extract of Arisaema jacquemontii Blume. J. Taibah Univ. Sci. 9:449-454, doi: 10.1016/ j.jtusci.2014.11.001.

Bantis, F., S. Smirnakou, T. Ouzounis, A. Koukounaras, N. Ntagkas, and K. Radoglou. 2018. Current status and recent achievements in the field of horticulture with the 
use of light-emitting diodes (LEDs). Scientia Hort. 235:437-451, doi: 10.1016/j.scienta.2018. 02.058 .

Björkman, O. 1981. Responses to different quantum flux densities, p. 57-107. In: O.L. Lange, P.S. Nobel, C.B. Osmond, and H. Ziegler (eds.). Physiological plant ecology I: Responses to the physical environment. Springer, Berlin, Heidelberg. https://doi.org/10.1007/ 978-3-642-68090-8_4.

Brazaitytè, A., P. Duchovskis, A. Urbonavičiūtè, G. Samuolienė, J. Jankauskiene, J. Sakalauskaite, G. Šabajevienè, R. Sirtautas, and A. Novičkovas. 2010. The effect of light-emitting diodes lighting on the growth of tomato transplants. ZemdirbysteAgr. 97(2):89-98.

Cavallini, F. 1993. Fitting a logistic curve to data. Coll. Math. J. 24(3):247-253, doi: 10.1080/ 07468342.1993 .11973540$.

Corral-Aguayo, R.D., E.M. Yahia, A. Carrillo-Lopez, and G. González-Aguilar. 2008. Correlation between some nutritional components and the total antioxidant capacity measured with six different assays in eight horticultural crops. J. Agr. Food Chem. 56(22):10498-10504, doi: 10.1021/ jf801983r.

Eguchi, T., R. Hernández, and C. Kubota. 2016. Far-red and blue light synergistically mitigate intumescence injury of tomato plants grown under ultraviolet-deficit light environment. HortScience 51:712-719, doi: 10.21273/ HORTSCI.51.6.712.

Evans, J. and H. Poorter. 2001. Photosynthetic acclimation of plants to growth irradiance: The relative importance of specific leaf area and nitrogen partitioning in maximizing carbon gain. Plant Cell Environ. 24(8):755-767, doi: 10.1046/j.1365-3040.2001.00724.x.

Fan, X.-X., Z.-G. Xu, X.-Y. Liu, C.-M. Tang, L.-W. Wang, and X.-L. Han. 2013. Effects of light intensity on the growth and leaf development of young tomato plants grown under a combination of red and blue light. Scientia Hort. 153:50-55, doi: 10.1016/j.scienta.2013. 01.017.

Gary, C., J. Jones, and J. Longuenesse. 1991. Modelling daily changes in specific leaf area of tomato: The contribution of the leaf assimilate pool. Acta Hort. 328:205-210, doi: 10.17660/ActaHortic. 1993.328.19.

Glowacka, B. 2002. Effect of light colour on the growth of tomato (Lycopersicon esculentum Mill.) transplant. Acta Sci. Pol. Hortorum Cultus 1(2):93-103.

Gómez, C. and C.A. Mitchell. 2015. Growth responses of tomato seedlings to different spectra of supplemental lighting. HortScience 50:112118, doi: 10.21273/HORTSCI.50.1.112.

Halvorsen, B.L. and R. Blomhoff. 2011. Validation of a quantitative assay for the total content of lipophilic and hydrophilic antioxidants in foods. Food Chem. 127(2):761-768, doi: 10.1016/j.foodchem.2010.12.142.

Hanson, H.C. 1917. Leaf-structure as related to environment. Amer. J. Bot. 4(9):533-560, doi: $10.2307 / 2435253$.

Haque, M.S., K.H. Kjaer, E. Rosenqvist, and C.O. Ottosen. 2015. Continuous light increases growth, daily carbon gain, antioxidants, and alters carbohydrate metabolism in a cultivated and a wild tomato species. Frontiers Plant Sci. 6:522, doi: 10.3389/fpls.2015.00522.

Hernández, R. and C. Kubota. 2012. Tomato seedling growth and morphological responses to supplemental LED lighting red: Blue ratios under varied daily solar light integrals. Acta Hort. 956:187-194, doi: 10.17660/ActaHortic.2012.956.19.
Kang, S., Y. Zhang, Y. Zhang, J. Zou, Q. Yang, and T. Li. 2018. Ultraviolet-A radiation stimulates growth of indoor cultivated tomato (Solanum lycopersicum) seedlings. HortScience 53:1429-1433, doi: 10.21273/ HORTSCI13347-18

Kim, E.-Y., S.-A. Park, B.-J. Park, Y. Lee, and M.M. Oh. 2014. Growth and antioxidant phenolic compounds in cherry tomato seedlings grown under monochromatic light-emitting diodes. Hort. Environ. Biotechnol. 55(6):506-513, doi: 10.1007/s13580-014-0121-7.

King, P.H. and J.R. Alvarez-Bada. 2020. Fundamentals of solid-state lighting: LEDs, OLEDs, and their applications in illumination and displays, p. 31-33. In: V.K. Khanna (ed.). IEEE Pulse. CRC Press/Taylor \& Francis, Boca Raton, FL. doi: https://doi.org/10.1109/ MPULS.2020.2984346.

Korkmaz, A. and R. Dufault. 2004. Differential cold stress duration and frequency treatment effects on muskmelon seedling and field growth and yield. Eur. J. Hort. Sci. 69(1):1220.

Kozai, T. 2007. Propagation, grafting and transplant production in closed systems with artificial lighting for commercialization in Japan. Propag. Ornam. Plants 7(3):145-149.

Lee, M.-J., K.-H. Son, and M.-M. Oh. 2016. Increase in biomass and bioactive compounds in lettuce under various ratios of red to far-red LED light supplemented with blue LED light. Hort. Environ. Biotechnol. 57(2):139-147, doi: 10.1007/s13580-016-0133-6.

Liu, J., W. Wang, L. Wang, and Y. Sun. 2015. Exogenous melatonin improves seedling health index and drought tolerance in tomato. Plant Growth Regulat. 77(3):317-326, doi: 10.1007/ s10725-015-0066-6.

Mariz-Ponte, N., R. Mendes, S. Sario, P. Melo, and C. Santos. 2018. Moderate UV-A supplementation benefits tomato seed and seedling invigoration: A contribution to the use of UV in seed technology. Scientia Hort. 235:357-366, doi: 10.1016/j.scienta.2018.03.025.

Matsuda, R., T. Yamano, K. Murakami, and K. Fujiwara. 2016. Effects of spectral distribution and photosynthetic photon flux density for overnight LED light irradiation on tomato seedling growth and leaf injury. Scientia Hort. 198:363369, doi: 10.1016/j.scienta.2015.11.045.

Matsuo, S., K. Nanya, S. Imanishi, I. Honda, and E. Goto. 2019. Effects of blue and red lights on gibberellin metabolism in tomato seedlings. Hort. J. 88(1):76-82, doi: 10.2503/hortj.UTD005 .

Mittler, R. 2002. Oxidative stress, antioxidants and stress tolerance. Trends Plant Sci. 7(9):405-410, doi: 10.1016/S1360-1385(02) 02312-9.

Nanya, K., Y. Ishigami, S. Hikosaka, and E. Goto. 2012. Effects of blue and red light on stem elongation and flowering of tomato seedlings. Acta Hort. 956:261-266, doi: 10.17660/ActaHortic.2012.956.29.

Nenadis, N. and M. Tsimidou. 2002. Observations on the estimation of scavenging activity of phenolic compounds using rapid 1,1 diphenyl-2-picrylhydrazyl (DPPH•) tests. J. Amer. Oil Chemists' Soc. 79(12):1191, doi: 10.1007/s11746-002-0626-z.

Olvera-Novoa, M.A., C. Martínez Palacios, and E. Real De León. 1993. Manual de tecnicas para laboratorio de nutricion de peces y crustaceos. Proyecto AQUILA II. Documento de Campo no. 7. FAO, Mexico.
OuYang, F., J.-F. Mao, J. Wang, S. Zhang, and Y. Li. 2015. Transcriptome analysis reveals that red and blue light regulate growth and phytohormone metabolism in Norway spruce [Picea abies (L.) Karst.]. PLoS One 10(8), doi: 10.1371/ journal.pone.0127896.

Ozgen, M., R.N. Reese, A.Z. Tulio, J.C. Scheerens, and A.R. Miller. 2006. Modified 2,2-azino-bis3-ethylbenzothiazoline-6-sulfonic acid (ABTS) method to measure antioxidant capacity of selected small fruits and comparison to ferric reducing antioxidant power (FRAP) and 2,2' diphenyl-1-picrylhydrazyl (DPPH) methods. J. Agr. Food Chem. 54(4):1151-1157, doi: 10.1021/ jf051960d.

Rai, N., A. O'hara, D. Farkas, O. Safronov, K. Ratanasopa, F. Wang, A.V. Lindfors, G.I. Jenkins, T. Lehto, and J. Salojärvi. 2020. The photoreceptor UVR8 mediates the perception of both UV-B and UV-A wavelengths up to $350 \mathrm{~nm}$ of sunlight with responsivity moderated by cryptochromes. Plant Cell Environ., doi: $10.1111 /$ pce. 13752 .

Rivero, R.M., J.M. Ruiz, and L. Romero. 2003. Can grafting in tomato plants strengthen resistance to thermal stress? J. Sci. Food Agr. 83(13):1315-1319, doi: 10.1002/jsfa.1541.

Singleton, V.L. and J.A. Rossi. 1965. Colorimetry of total phenolics with phosphomolybdicphosphotungstic acid reagents. Amer. J. Enol. Viticult. 16(3):144-158.

Son, K.-H., E.-Y. Kim, and M.-M. Oh. 2018. Growth and development of cherry tomato seedlings grown under various combined ratios of red to blue LED lights and fruit yield and quality after transplanting. Protected Hort. Plant Factory 27(1):54-63.

Soobrattee, M.A., V.S. Neergheen, A. LuximonRamma, O.I. Aruoma, and T. Bahorun. 2005. Phenolics as potential antioxidant therapeutic agents: Mechanism and actions. Mutat. Res. Fundam. Mol. Mech. Mutagen. 579(12):200-213, doi: 10.1016/j.mrfmmm.2005. 03.023 .

Strickland, J.D. and T.R. Parsons. 1972. A practical handbook of seawater analysis. Fisheries Research Board of Canada.

Thimijan, R.W. and R.D. Heins. 1983. Photometric, radiometric, and quantum light units of measure: A review of procedures for interconversion. HortScience 18:818-822.

Vázquez-Hernández, M.C., I. Parola-Contreras, L. Montoya-Gómez, I. Torres-Pacheco, D. Schwarz, and R.G. Guevara-González. 2019. Eustressors: Chemical and physical stress factors used to enhance vegetables production. Scientia Hort. 250:223-229, doi: $10.1016 /$ j.scienta.2019.02.053.

Velez-Ramirez, A.I., G. Dünner-Planella, D. Vreugdenhil, F.F. Millenaar, and W. Van Ieperen. 2017. On the induction of injury in tomato under continuous light: Circadian asynchrony as the main triggering factor. Funct. Plant Biol. 44(6):597-611, doi: 10.1071/ FP16285.

Villano, D., M. Fernández-Pachón, M. Moyá, A. Troncoso, and M. García-Parrilla. 2007. Radical scavenging ability of polyphenolic compounds towards DPPH free radical. Talanta 71(1):230-235, doi: 10.1016/j.talanta.2006. 03.050 .

Xiaoying, L., G. Shirong, C. Taotao, X. Zhigang, and T. Tezuka. 2012. Regulation of the growth and photosynthesis of cherry tomato seedlings by different light irradiations of light emitting diodes (LED). Afr. J. Biotechnol. 11(22):6169-6177, doi: 10.5897/ AJB11.1191. 
Xu, Y. 2019. Nature and source of light for plant factory, p. 47-69. In: M. Anpo, H. Fukuda, and T. Wada (eds.). Plant factory using artificial light. Elsevier. https://doi.org/10.1016/B978-012-813973-8.00002-6.

Yang, Z.-C., C. Kubota, P.-L. Chia, and M. Kacira. 2012. Effect of end-of-day far-red light from a movable LED fixture on squash rootstock hypocotyl elongation. Scientia Hort. 136:81-86, doi: 10.1016/j.scienta.2011.12.023.

Yu, Q., J. Liu, Y. Zhang, and J. Li. 2002. Simulation of rice biomass accumulation by an extended logistic model including influence of meteorological factors. Intl. J.
Biometeorol. 46(4):185-191, doi: 10.1007/ s00484-002-0141-3.

Zhishen, J., T. Mengcheng, and W. Jianming. 1999. The determination of flavonoid contents in mulberry and their scavenging effects on superoxide radicals. Food Chem. 64(4):555-559, doi: 10.1016/S0308-8146(98)00102-2. 